\title{
Gambling Addiction, Impulsive Behavior and Depression Amongst Civil Servants in Malaysia
}

\author{
Rozmi Ismail \& Nordin Abdul Hamid
}

To Link this Article: http://dx.doi.org/10.6007/IJARBSS/v11-i6/10229

DOI:10.6007/IJARBSS/v11-i6/10229

Received: 19 April 2021, Revised: 23 May 2021, Accepted: 04 June 2021

Published Online: 20 June 2021

In-Text Citation: (Ismail \& Hamid, 2021)

To Cite this Article: Ismail, R., \& Hamid, N. A. (2021). Gambling Addiction, Impulsive Behavior and Depression Amongst Civil Servants in Malaysia. International Journal of Academic Research in Business and Social Sciences, 11(6), 993-1005.

\section{Copyright: (c) 2021 The Author(s)}

Published by Human Resource Management Academic Research Society (www.hrmars.com)

This article is published under the Creative Commons Attribution (CC BY 4.0) license. Anyone may reproduce, distribute, translate and create derivative works of this article (for both commercial and non-commercial purposes), subject to full attribution to the original publication and authors. The full terms of this license may be seen at: http://creativecommons.org/licences/by/4.0/legalcode

\section{Vol. 11, No. 6, 2021, Pg. 993 - 1005}

Full Terms \& Conditions of access and use can be found at http://hrmars.com/index.php/pages/detail/publication-ethics 


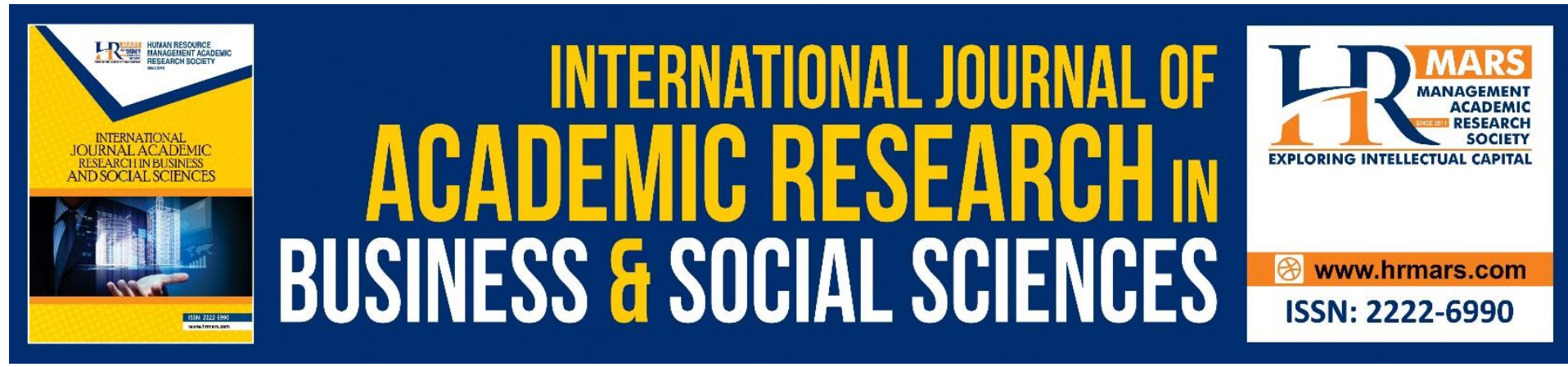

\title{
Gambling Addiction, Impulsive Behavior and Depression Amongst Civil Servants in Malaysia
}

\author{
Rozmi Ismail \& Nordin Abdul Hamid
}

Center for Research in Psychology and Human Well-Being, Faculty of Social Science and Humanities, The National University of Malaysia, 43600 Bangi, Selangor, Malaysia

Email: rozmi@ukm.edu.my

\begin{abstract}
Latest trends show online gambling began to take over the place of gambling premises. Today, gambling syndicates used tablets and smart phones as a medium for online to ensure their operations is sustained and cannot be detected by the enforcement authorities. Gambling addiction is a compulsive behaviour, where someone is addicted to keep betting and bidding despite the negative consequences they have suffered in the past. This paper presents research on the relationship between internet gambling addiction, impulsive personality and depression amongst civil servants whom involved in online gambling. There were 125 male respondents with highly addicted to online gambling volunteered to participate in our survey. The study used Problem Gambling Severity Index (PGSI), Barratt Impulsiveness Scale (BIS) and Depression Anxiety Stress Scale (DASS). The results of Pearson correlation showed that gambling addiction significantly correlated with depression and impulsive trait. Results of linear regression showed impulsivity significantly predict $80 \%$ of the variance in gambling addiction and became the dominant variable, whilst depression forecast $69 \%$ of the variance. The implication of this study implies that since impulsive personality and depression symptoms are very important factors in understanding online gambling addiction thus, any form of treatment or prevention should focus on these two aspects.
\end{abstract}

Keywords: Online Gambling, Addiction, Impulsivity Personality, Depression, Civil Servant

\section{Introduction}

Over the last 15 years there has been a significant change to the gambling environment where internet gambling including the use of mobile phone becomes very popular. Internet gambling is the fastest growing mode of gambling and is changing the way that gamblers engage with this activity. The online global gambling market was valued at $€ 6.1$ billion in 2013 , with expected annual growth of $10.1 \%$ in 2018 (Global Gaming Report, 2018). Online gambling accounted for an estimated $8-10 \%$ of the total global gambling market in 2012, and this proportion appears to be increasing. Global online gambling market is projected to grow at a CAGR of 8.77\%, during the forecast period of 2019 - 2024 (Global Gaming Report, 2018). Globally, the largest online gambling product is wagering, accounting for $53 \%$ of the online gambling market, followed by casino games (including slot machines, pokies, electronic gaming machines, $25.4 \%)$, poker (14.2\%), and bingo (7.4\%). Online gambling became a trend 
nowadays as a result to unlimited internet access and the person is free to gamble comfortably at home because of internet access facilities (Wood and Williams, 2011). Research suggests that the most commonly reported motivators and advantages of Internet gambling are the convenience and accessibility of this mode. Other commonly stated advantages of Internet gambling include greater value for money, including payout rates and bonuses, the speed and ease of online gambling, greater number of betting products and options and the physical comfort of being able to gamble from home. The prevalence of gambling problem in Malaysia is estimated about $4.4 \%$ of the population were categorized as problem gamblers while $10.2 \%$ were moderate-risk gamblers. This prediction signifies that approximately 246,400 Malaysians in Selangor are potentially problem gamblers while 571,200 are moderate-risk problem gamblers (Loo and Ang 2013). Although participating in gambling activities and the prevalence rates are comparatively on the higher end of the spectrum compared to other Asian populations, which report problem gambling rates ranging from 1.4 to $2.5 \%$ (Blaszczynski et al., 1998).

Addiction to online gambling is not much different with drug or alcohol addiction. According to the DSM-IV classification by the American Psychiatric Association (1994) gambling addiction belongs to the type of mental illness called impulse control disorder. Patients at least have five of the following features; have a very strong memory to gamble, always increasing the amount of betting to win money; regularly failed to stop or reduce gambling; became restless and irritability when trying to stop and gamble to resolve financial problems or arousal from the winning feelings. Nowak \& Aloe (2014) reported that gambling addiction online gain more risks compared to other gambling habits. Gambling addiction is a compulsive behaviour, where someone is addicted to keep betting and bidding despite the negative consequences he or she suffered in the past (Gainsbury, 2015). Study showed that impulsive personality are relates to the behaviour of gambling especially risk-taking behaviour (Evenden, 1999). Impulsivity traits developed through three characteristics and perspectives, different cognitive, behaviour and character. According to Eysenck (1985) impulsive behaviours related to taking risks, lack of planning for something things and risky decision making.

Other studies have showed that there was a relationship between gambling addiction and depression disorders. Studies by Barrault (2013); Petry (2001); Canale et al, (2015) showed that individuals with depression are more vulnerable to addiction three times higher than individuals who do not have depression. Gambling is often use as an agent to reduce the problem of depression and increase motivation (Moore, 2002). Individuals with depression also reported chooses not to take medication supplied due to side effects of medication, however, choosing gambling as an alternative to the depression treatment (Kathleen Moore, 2002). Factors such as 'excited' in some gambling games can cause an increase in dopamine, thus forcing people to choose gambling as an alternative treatment. American Psyhiatric Association (APA) has placed ' Gambling Disorder ' in the group along with substance abuse and addiction problems in the DSM-5 (Petry et. al., 2013). There are evidences showed that gambling satisfaction equal to other addictions and tends to cause the same behaviour problems with other addiction (Petry et. al, 2013). Study by Petry (2001); Canale et al, (2015) found that gambling addiction were related to impulsive traits, and such addictions are similar to drug abuse in terms of linear time orientation and impulse control. 
Those individuals who involved in gambling addiction generally act impulsively with problem and seen to have low levels in decision making and more conscious instant rewards. As pointed out by Braverman (2010) in his study using 69 respondents found that gambler with high frequency and intensity more frequently reported have gambling addiction when their online account closed. Phyllis (2013) also found that majority of gamblers in Hong Kong have an addiction problem and impulsive personality as well as low level of psychosocial. Gambling is a dominant culture in Hong Kong and way of socializing. Findings from the study found low levels of psychosocial individual using gambling as an alternative for socializing in the community. Nordin (2007) demonstrated that gambling is a kind of entertainment which if they win, they get compliments and better known in the community. Thus, making gambling as a way to socialize, individuals who possess high impulsive personality traits are exposed to gambling addiction (Nordin et al., 2007). The study by McCormick (1988) found some gamblers with low coping skills recorded more depress as a result of gambling. Barrault (2013) also found that there was a significant relationship between individuals with gambling addiction problem and depression disorders.

Gambling addiction can also be explained through neurobiology factors. Research by Potenza (2013) showed an increase hormone non-adrenaline among individuals with gambling addiction and increased biological stimulation while gambling that create feelings of excitement and fun. The study also described individuals with gambling addictions have low Serotonin hormone levels just as individual with depression and Dopamine and Norepinephrine hormones increased to create a feeling of happy and improve motivation during gambling cause individuals to continue to gambling that eventually addictive. The study by Weatherly (2013) found that there are differences in young and old age while gambling, where young people make gambling as a way out of their problems especially in finance, but for the old age it is part of entertainment. Effect of making gambling as a way out of the problem will cause them often to play and eventually become addicted to gambling. Study by Natale et al (2017) showed that winning and defeat when gambling correlated with Impulsivity personality. Individuals who gamble did not use rational thinking in making the decision to gamble again. The findings also showed individuals at high risk of impulsive personality tend to make risky decisions. The relationship between impulsivity can be seen when individuals obtain a loss will gamble to win back the missing money. The study also shows though is often lost, individuals will continue to play as they believe victory will overcome total defeat. Study by Mario (2014) to measure testosterone hormone levels when individuals loose and win found that testosterone levels changes to low while the loose and rise during the win. Study by Laube (2017) also found that the testosterone hormone increased as the sensitivity to get instants rewards increased. Another Study by Mariya (2018) using 131 respondents showed an increase in winning value and the winning frequency may result in risk decision making and also increase the stimulus when each time their gambling. Nower \& Blaszczynski (2006) showed that impulsivity played a major role in the gambling addiction through several aspects such as quick decision making regardless of their impact and consequences more likely to choose risky decisions and always looking for attention. Individuals who own a trait of 'non-planning' or impulsivivity have a character to act without thinking, careless and love to enjoy more likely with gambling addiction.

Based on the previous findings, gambling addiction is caused by a complex interaction between trait impulsivity personality and environmental conditions with cognition and 
affective variable. Individuals with high impulsivity personality is predicted to be more interested in instant rewards more than rewards require time to get it before they started gambling. From the theoretical perspectives, gambling environment associated with feelings of excitement through classical conditioning, and this excitement becomes a conditioned reinforce for continued gambling behaviour. Furthermore, the greater the size of the reward, the more resistant the behaviour will be to extinction. Thus, gamblers who experience large rewards early in their gambling career may be more susceptible to developing gambling problems (Skinner,1969). Thus, the objective of this study is to examine relationship between gambling addiction and depression and also to examine what are the factors that can predict online gambling addiction amongst the civil servant in Malaysia.

\section{Method}

Respondents; There were 125 men with age between $18-52$ years old took part in the study. The design of the studies using quantitative approach through survey method. The questionnaires were distributed to the selected respondents through snowballing sampling technique.

Instruments; The instruments used for this study were; 1) Problem Gambling Severity Index (PGSI) questionnaire to assess the level of gambling addiction among respondents. The PGSI consist of Likert scale 0-3 $=$ no problem gambling, $1-2=$ low, 3-7 = medium and $>8=$ severe gambling problems (Thomas Holtgraves, 2008); 2) Barratt Impulsiveness Scale (BIS) version 11(30 items) used to measure impulsivity trait among respondent including Attentional, Motor and Non-planning impulsivity. The DASS Malay version (21 items) developed by Ramli Musa (2011) the test consisted of depression, Anxiety and Stress where the scale results are Normal (Normal), Mild (Mild), Moderate (Medium), Severe (Severe) and Extremely Severe (very badly). This test is used to evaluate the respondent depression status. Reliability tests of the instruments was conducted and found that all variables could pass standard range Cronbach's Alpha in excess of 0.7 , which is the value of the coefficient of reliability in excess of 0.7 is considered to be sufficient. All instruments have been verified through back to back translation by expert. Table 1 shows the value of reliability assessment tools used.

Table 1. Cronbach's Alpha value

\begin{tabular}{cc}
\hline TEST & Cronbach's Alpha \\
\hline PGSI & 0.831 \\
BIS-11 & 0.976 \\
DASS & 0.713 \\
\hline
\end{tabular}

Study Location; The study was conducted in Malacca, one of the states located in south of Peninsular Malaysia. Respondents made up of government staff in Bukit Baru, Malacca. Before the study is conducted, preliminary visit and rapport was built between researcher and respondents. Preliminary visits are very important to develop rapport, trust and cooperation from respondents.

\section{Results}

Results in Table 2 shows the number of respondents involved in this study. More than $70 \%$ of respondents were aged 30 years and above. Majority of respondents were married and with 
monthly income about RM3000 a month. In terms of level of education, majority of respondents had SPM (Malaysian Certificate Secondary) and 39 respondents had diploma.

Table 2 Demographic characteristics of the respondents

\begin{tabular}{|c|c|c|c|}
\hline No & Category & Frequencies & $\begin{array}{c}\text { Percentage } \\
\%\end{array}$ \\
\hline \multirow[t]{5}{*}{1} & AGE & & \\
\hline & $20-29$ & 25 & 20 \\
\hline & $30-39$ & 46 & 36.8 \\
\hline & $40-49$ & 44 & 35.2 \\
\hline & $>50$ & 10 & 8 \\
\hline \multirow[t]{5}{*}{2} & INCOME & & \\
\hline & $<2000$ & 26 & 20.8 \\
\hline & $2001-3000$ & 52 & 41.6 \\
\hline & $3001-4000$ & 44 & 35.2 \\
\hline & $>4001$ & 3 & 2.4 \\
\hline \multirow[t]{7}{*}{3} & EDUCATION & & \\
\hline & PMR & 3 & 2.4 \\
\hline & SPM & 69 & 55.2 \\
\hline & SIJIL & 12 & 9.6 \\
\hline & DIPLOMA & 39 & 31.2 \\
\hline & IJAZAH & 2 & 1.6 \\
\hline & OTHERS & 0 & 0 \\
\hline \multirow[t]{3}{*}{4} & MARITAL STATUS & & \\
\hline & SINGLE & 37 & 29.6 \\
\hline & MARRIED & 88 & 70.4 \\
\hline
\end{tabular}

With regard to the involvement in gambling activity, Table 3 shows the frequency of winning the game within a month. The results show that a total of $73.6 \%$ or 92 of the respondents reported winning between six to 10 times a month, 20 respondents (16\%) between one and five times a month and 13 respondents which is $10.4 \%$ of respondents reported winning frequencies 11 to 15 times a month. Whereas Table 4 shows the amount of money they received prior to win the game. About 42 respondents or $33.6 \%$ acquire RM501 to RM1000 in one victory, 40 respondents (32\%) acquire RM101 and RM500, 38 respondents (30.4\%) were earn more than RM1001 and a total of five respondents or $4 \%$ winning less than RM100.

Table 3. Winning frequencies in a month Frequencie Percentag

\begin{tabular}{ccc} 
Scale & s & e \% \\
\hline $1-5$ & 20 & 16 \\
$6-10$ & 92 & 73.6 \\
$11-15$ & 13 & 10.4 \\
\hline Total & 125 & 100 \\
\hline
\end{tabular}

Table 4. Winning Value (Malaysia Ringgit)

\begin{tabular}{|c|c|c|}
\hline Scale (RM) & Frequencies & $\begin{array}{c}\text { Percentage } \\
\%\end{array}$ \\
\hline$<100$ & 5 & 4 \\
\hline $101-500$ & 40 & 32 \\
\hline $501-1000$ & 42 & 33.6 \\
\hline$>1001$ & 38 & 30.4 \\
\hline Total & 125 & 100 \\
\hline
\end{tabular}


Analysis on instruments (depression, impulsivity and PGSI) presented in Table 5, 6, 7) showed that for the PGSI about $53.6 \%$ respondents have scored at severe addiction range, whereas $46.4 \%$ of the respondents scored at moderate addiction. Results of BIS-11 showed that majority of respondents have tended to be as Non-Planning (26.59) and Motor-behaviour intention (25.78). Whereas for the DASS, about 49 (39\%) of respondents scored high in depression subscales, $58(45.4 \%)$ respondents scored at moderate and $18(15 \%)$ respondents scored low level of depression.

Table 5. PGSI score frequencies

\begin{tabular}{ccc}
\hline PGSI Score & Frequencies & $\begin{array}{c}\text { Percentag } \\
\text { e } \%\end{array}$ \\
\hline 0 & 0 & 0 \\
1 To 2 & 0 & 0 \\
3 To 7 & 58 & 46.4 \\
$>8$ & 67 & 53.6 \\
\hline Total & 125 & 100 \\
\hline
\end{tabular}

Table 6. Mean Score for Impulsivity

\begin{tabular}{cc}
\hline Factor & Mean \\
\hline Attention & 17.9600 \\
Moto & 25.7840 \\
Non Planning & 26.5680 \\
\hline
\end{tabular}

Table 7. Frequencies score for DASS

\begin{tabular}{ccc}
\hline SCORE & FREQUENCY & $\begin{array}{c}\text { PERCENTAGE } \\
\%\end{array}$ \\
\hline 0 to 5 & 0 & \\
6 to 7 & 18 & 14.4 \\
8 to 10 & 58 & 45.4 \\
11 to 14 & 49 & 39.2 \\
$>15$ & 0 & \\
\hline TOTAL & 125 & 100 \\
\hline
\end{tabular}

An Independent samples t-test was carried out to compare the mean value between different group of respondents according to their educational status and the results showed no significant difference. A Pearson correlation test was also performed to test the relationship between variables pertaining to gambling addiction. Results showed that gambling addiction significantly correlated with impulsivity traits $(r=0.892, p=.01)$ and depression $(r=0.829$, $p=.01)$. Gambling addiction also significantly correlated with the winning frequency $(r=0.466$, $p=.01)$ and largest winning value $(r=0.327, p=0.01)$.

Further analysis using regression was carry out to examine which factors can predict gambling addiction. Result from table 10 shows the relationship between impulsivity trait and online gambling addiction. Model summary in table 10 showed that Impulsivity personality significantly predicted gambling addiction $(p<0.05)$ and accounted for $80 \%(.796)$ of impulsive personality changes are within gambling addiction variations. Another interesting finding is that depression was significantly associated with online gambling addiction. Model summary in Table 11 showed that depression accounted for $69 \%\left(.687^{*} 100\right)$ of the total variance in predicting gambling addiction. 
Table 10. Linear Regression of Impulsivity Personality with Gambling Addiction

\begin{tabular}{ccccccc}
\hline \multirow{2}{*}{ Model } & $\begin{array}{c}\text { Sum of } \\
\text { Squares }\end{array}$ & df & $\begin{array}{c}\text { Mean } \\
\text { Square }\end{array}$ & $F$ & Sig. \\
\hline \multirow{2}{*}{1} & Regression & 2106.46 & 1 & 2106.46 & 480.863 & $.000^{\text {b }}$ \\
& Residual & 538.706 & 123 & 4.380 & & \\
\hline & JUMLAH & 2644.752 & 124 & & & \\
\hline
\end{tabular}

a. Dependent Variable: JUDI

b. Predictors: (Constant), IMPULSIF

Model Summary

\begin{tabular}{ccccc}
\hline Model & $\mathrm{R}$ & R Square & $\begin{array}{c}\text { Adjusted R } \\
\text { Square }\end{array}$ & $\begin{array}{c}\text { Std. Error of the } \\
\text { Estimate }\end{array}$ \\
\hline 1 & $.892^{\mathrm{a}}$ & .796 & .795 & 2.09278 \\
\hline
\end{tabular}

a. Predictors: (Constant), TTLIMP

Coefficients

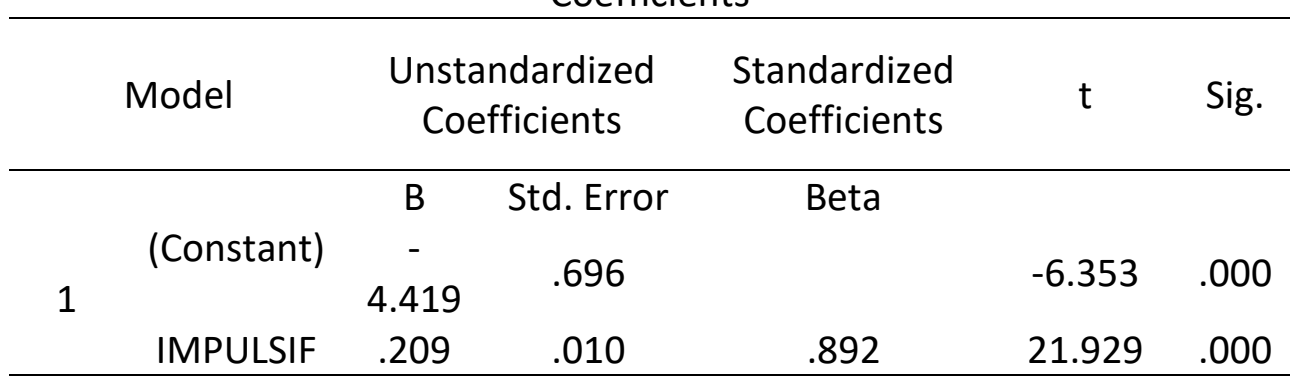

a. Dependent Variable: JUDI

Table 11. Model of Summary Linear Regression Between Depression and Online Gambling Addiction

\begin{tabular}{ccccccc}
\multicolumn{1}{c}{ ANNOVA } \\
\hline \multirow{2}{*}{ Model } & $\begin{array}{c}\text { Sum of } \\
\text { Squares }\end{array}$ & df & $\begin{array}{c}\text { Mean } \\
\text { Square }\end{array}$ & F & \multirow{2}{*}{ Sig. } \\
\hline \multirow{2}{*}{1} & Regression & 1817.210 & 1 & 1817.210 & 270.097 & $.000^{\mathrm{b}}$ \\
& Residual & 827.542 & 123 & 6.728 & & \\
\hline & JUMLAH & 2644.752 & 124 & & & \\
\hline
\end{tabular}

a. Dependent Variable: GAMBLE

b. Predictors: (Constant), DASS

Model Summary

\begin{tabular}{ccccc}
\hline Model & $\mathrm{R}$ & R Square & $\begin{array}{c}\text { Adjusted } \mathrm{R} \\
\text { Square }\end{array}$ & $\begin{array}{c}\text { Std. Error of the } \\
\text { Estimate }\end{array}$ \\
\hline 1 & $.829^{\mathrm{a}}$ & .687 & .685 & 2.59384 \\
\hline
\end{tabular}

a. Predictors: (Constant), DASS 
Coefficients

\begin{tabular}{ccccccc}
\hline Model & \multicolumn{1}{c}{$\begin{array}{c}\text { Unstandardized } \\
\text { Coefficients }\end{array}$} & $\begin{array}{c}\text { Standardized } \\
\text { Coefficients }\end{array}$ & t & Sig. \\
\hline 1 & B & Std. Error & Beta & & \\
\hline & (Constant) & -5.632 & 0.995 & & -5.660 & .000 \\
DASS & 1.608 & 98 & .829 & 16.435 & .000 \\
\hline
\end{tabular}

a. Dependent Variable: GAMBLING

\section{Discussion}

The aim of study is to examine the relationship between impulsivity personality and depression with online gambling addiction. A negative significant correlation between age and gambling addiction showed the higher level of gambling addiction associated with younger respondents. This are accordance to Weatherly (2013) as they found young gamblers more vulnerable to gambling addiction than adults and younger respondents gamble to get money whereas older gamblers were doing for fun or as recreation. The present study found frequency of winning significantly correlated with gambling addiction, impulsive personality and depression. The majority of respondents stated won the game between 6 to 10 times within a month. Desire to win is the main thing that helps increase the level of gambling addiction among respondents. Respondents who won between 6 to 10 times within a month be seen try to recover money they lost, indirectly, the negative reinforcement existed from these situations cause the addiction (Koob, 2016). Frequency of winning significantly affects individuals to make risky decisions, which is one of the factors in impulsivity personalities encouraging to risky decision-making (Mariya, 2018). Depression also significantly correlated with frequency of winning. This can be explained when gambling is seen as a way out to overcome depression. According to Blaszczynski (2006) the increasing frequency of winning seen able to help individuals who suffer from depression thus causing the individual forgets the problems they face. The major finding of this current study is a significant relationship between impulsivity personality and online gambling addiction. Results of linear regression also found that impulsivity personality strongly predicts gambling addiction ( $80 \%$ of the total variance). The findings are accordance with Potenza (2013) who found individuals with gambling addiction problem with an impulsivity personality tend to go back gambling again even he is still under treatment for gambling addiction. Neurobiology factors among individuals who are impulsive also play a central role in predicting the behaviour of gambling and probability level of gambling addiction. As indicated in the question number 17 of the BIS-11 "I act on impulse" means the individual act by impulse or impulsive and question no 2 "I do things without thinking" shows the individual acts without thinking about cause and effect with the majority of the respondents answered "often" and "very frequent".

This is supported by Potenza (2013) personality factors indicate hormone Norepinephrine (NE) functions as a cause factor individual search for attention, body stimulation and 'impulse ' as well for the focus. The findings also showed an increase in hormones NE in every subject with a gambling addiction. The findings also show mean for non-planning impulsive factor higher than the mean for motor and attention impulsive. The findings also indicate many respondents who acted without thinking about long-term effects that lead to problem gambling addiction. The data reinforced with question number nine from PGSI questionnaire 
"have you ever feel guilty over what happened to the effects of the gamble?" with a majority of respondents answer rarely. Researchers are also testing the fourth question in the BIS-11 I'm a cheerful with a majority of respondents answer ' frequently ' and 'very often '. Blaszczynski (2006) in his research shows there is a strong correlation between personality impulsive unplanned with individuals who had the character to act without thinking, careless and playful with gambling addiction.

Another interesting finding is that depression significantly predicted participants' ratings of gambling addiction. Correlation test showed a positive relationship between gambling addiction and depression. The results of the regression indicated depression predictors explained $69 \%$ of the variance. About 49 respondents had higher depression scores while 42 respondents answered 'regular' and 'very often' for the second question of PGSI questionnaire "Still thinking about the last 12 months, have you needed to gamble with larger amounts of money to get the same feeling of excitement?" may able to explain the feeling and biochemistry reaction which lead to gambling addiction. Through past research review, gambling is seen as an alternative for entertainment. This finding is accordance to Barrault (2013)' study where individual involve in gambling activity is to run away from the problems and as a therapy to calm. Previous studies by McCormick (1988) found problems with depression, lack of coping skills is the main cause in gambling addiction through biochemical reactions resulting in joy while gambling. This situation may be explained through the level of serotonin in individuals with problems of depression and at the same time gambling can increase dopamine and norepinephrine hormone that works to improve passion, motivation, focus and joy. Serotonin activity is associated with behavioural inhibition, emotional stabilization, sensory activity and cognitive function. Potenza (2013) in his research found decrease serotonin levels factors in individual who have a gambling addiction can cause them to return gambling which can increased oxytocin, Dopamine and norepinephrine hormone which acts as antidote to them.

The analysis also shows the value of winning has a significant relationship with gambling addiction, impulsivity personality and depression. The relationship between the values of the winning with a gambling addiction can be viewed from cognitive aspect when individuals earn the high winning value more likely to repeat the bet because thought the opportunity to win is increasing. Frequency to repeat the bets also causes gambling addiction. Testosterone hormone are one of the catalysts in impulsivity personality. As found Laube (2017) Dolan (2001) the value of the winning will increase testosterone hormone and help to increase the level of sensitivity to the value and instant rewards and aggressive behaviour towards winning the game. Despite interesting findings this study has some limitations for example the stigma in society against gambling addiction indirectly effect researchers to obtain respondent and the differences in terms of games involved, individual skills and different levels of pleasure. Overall, this study provides the basis for describing the empirical relationship factors in depression and impulsivity personality on problem gambling addiction. The findings of this study is also very important in terms of clinical problems to cure this addiction. The effects and relationship between depression and gambling addiction needs to be treated right away to prevent individuals with gambling addiction problem becomes more chronic, which can result in suicide case and criminal cases involving impulsive factors. 


\section{Conclusion}

Studies regarding gambling addiction and mental health in Malaysia are lacking, especially on the relationship between depression and impulsivity. Most of the studies previously viewed depression as the effects or consequences of gambling addiction. This study has provided early findings about a looming problem gambling addiction in involving civil servants. Overall, this study has found that individuals with gambling addiction problem had high impulsivity and depression levels. Demographic data indicates individuals with income below RM4000 more involved in gambling that ultimately lead to addiction. This may be due to stress factors that lead to depression in the lead now where increasing cost of living has become a major problem in Malaysia. For impulsivity personality, can be seen here, this variable plays an important role in addictive gambling through frequency of gamble and bet without thinking about the effects and consequences. The study also found that depression and attitude of individuals who choose gambling as a treatment may be due to lack of exposure and early treatment for the symptoms of depression. As we know, Malaysians still has a stigma to mental illness resulting in failure to detect individuals with depressive problems in advance. Therefore, the cooperation of all parties to assist and support individuals with depression is likely to be reduced to the problem of this addiction.

\section{Acknowledgement}

Special thanks to all respondents participating in this study and also The Universiti Kebangsaan Malaysia for assisting this study.

\section{References}

American Psychiatric Association (APA). (2013). From Planning to Publication: DSM-5. Barbie, E., and Mouton, J. (2001). The Practice of Social Research Oxford University Press Cape Town.

Blaszczynski, A. (1996). A Pathological gambling and obsessive-compulsive spectrum disorders. Psychol Rep; 84:107-113.

Blaszczynski, A., Huynh, S., Dumlao V. J., \& Farrell, E. (1998). Problem gambling within a Chinese speaking community. Journal of Gambling Studies, 14(4):359-380. doi: 10.1023/A:1023073026236.

Nower, L., \& Blaszczynski, A. (2006). Impulsivity and Pathological Gambling: A Descriptive Model June 2006International Gambling Studies 6(1):61-75, DOI: $10.1080 / 14459790600644192$

Canale, N., Vieno, A., Griffiths, M. D., Rubaltelli, E., \& Santinello, M. (2015). Trait urgency and gambling problems in young people by age: The mediating role of decision-making processes. Addictive Behaviors. Vol 46. 39-44.

Laube, C. A. B. (2017). Dissociable Effects of Age And Testosterone on Adolescent Impatience. Psychoneuroendocrinology. 162-169.

Dolan, M. I. (2001). Relationship Between 5-HT Function and Impulsivity and Aggression in Male Offenders with Personality Disorder. British Jurnal of Psychiatry, 352-359.

Eysenck, H. P. (1985). Age Norm For Impulsiveness, Venturesomeness and Emphaty In Adult, Personality and Individual Different. Vol 6. 613-619.

Evenden, J. I. (1999). Impulsivity: a discussion of clinical and experimental findings. Joural of Psychopharmacology.13(2):180-92.

Gainsbury, S. M. (2015). Online Gambling Addiction: The Relationship Between Internet Gambling and Disordered Gambling. Curr Addict Rep 2, 185-193. 
Braverman, H., \& Shaffer. J. (2010). How do gamblers start gambling: identifying behavioural markers for high-risk internet gambling. European Journal of Public Health. Vol. 22, No. 2, 278-280

Kathleen, M., Matthews, C., Michael, H., \& Pape. L. (2002). Co-occurring Disorders Problem Gambling Integrated Treatment Workbook. The Louis de la Parte Florida Mental Health Institute, University of South Florida.

Loft, M. H., \& Loo, J. M. Y. (2015). Understanding the mechanisms underlying gambling behaviour and sleep. Journal of Gambling Studies, 31(4), 1273-1286.

Loo, J. M. Y., \& Ang, K.T. (2013). Prevalence of problem gambling in Selangor urban areas. Kuala Lumpur: Monash University Malaysia \& Malaysian Mental Health Association; 2013.

Nower, L., \& Blaszczynski, A. (2006). Impulsivity and Pathological Gambling: A Descriptive Model. International Gambling Studies, Vol. 6, No. 1, 61-75

Mario, A. F. (2017). Slot Machine Gambling and Testosterone. Evidence For 'Winner-Loser' Effect? Unpublished Thesis. University of British Columbia.

Mariya, V. C., Clark, L., Jason, J., Barton, S., Schulzer, M., Shafiee, M., Kingstone, A., JonStoessl, A., \& Winstanl, C. A. (2018). Win Concurrent Sensory Cues Can Promote Riskier Choice. The journal Of Neuroscience. Vol 38(48),10362-10370

Mccormick, R. A. (1988). Pathological gambling; a parsimonious need state model. Journal of Gambling Behavior. vol 3, 257-263

Petry, M. C. (2001). Drug and Alcohol Dependence. vol 63. 29-38

Natale, C., Rubaltelli, E., Vieno, A., Pittarello, A., \& Billieux, J. (2017). Impulsivity infuences betting under stress in laboratory gambling. Scientific report online. nature.volume 7 , Article number: 10668, 2017.

Nestler, E. J. (2013). "Cellular basis of memory for addiction". Dialogues Clin. Neurosci. Vol 15(4): 431-443.

Nordin, C., \& Nylander, P. O. (2007). Temperament and character in pathological gambling. Journal of Gambling Studies. vol 23, 113-120

Nowak, D. E., \& Aloe, A. M. (2014). The prevalence of pathological gambling among college students, Journal of Gambling Studies. vol 30. 819-843.

Petry, N. M., \& O'Brien, C. P. (2013). Internet gaming disorder and the DSM5. Addiction. vol 108. 1186-1187

Petry, N. M., Blanco, C., Stinchfield, R., \& Volberg, R. (2013). An empirical evaluation of proposed changes for gambling diagnosis in the DSM-5 Addiction, Volume 108, Issue3, 575-581.

Tung, P. W. M. (2013). Personality Traits as Predictors of Pathological Gambling in Hong Kong. California School of Professional Psychology.

Potenza, M. N. (2013). Neurobiology of gambling behaviour. Current Opinion in Neurobiology, 23(4), 660-667. Doi 10.1016/j.com.2013.03.004

Ramli, M., Ariff, M. F., \& Zaini, Z. (2007). Translation, validation and psychometric properties of Bahasa Malaysia version of the Depression Anxiety and Stress Scales (DASS), ASEAN Journal of Psychiatry 2007. Vol 8(2):82-89. Faculty of Medicine, Universiti Teknologi MARA, Selangor.

Ramli, M., Roszaman, R., Kartini, A., Rosnani, S. (2011). Concurrent Validity of The Depression Anxiety and Stress Scales (DASS). ASEAN Journal of Psychiatry. Vol.12(1), Jan-June 
Barrault, S. (2013). Cognitive Distortions, Anxiety, and Depression Among Regular and Pathological Gambling Online Poker Players. Cyberpsychology, Behavior, And Social Networking. Volume 16, Number 3.

Skinner, B. F. (1969). Contigencies of Reinforcement: A Theoretical Analysis. Engelwood Cliffs, NJ: Prenice-Hall, Inc.

Thomas, H. (2008). Evaluating the Problem Gambling Severity Index. Journal of Gambling Study, vol 25:105-120

Koob, G. F., Volkow, N. D., \& McLellan, A. T. (2016). "Neurobiologic Advances from the Brain Disease Model of Addiction". N. Engl. J. Med. Vol 374(4): 363-371.

Weatherly, J. N. (2013). Comparing the contingencies that maintain gambling behaviour in an online sample of younger and older adults. Analysis of Gambling Behavior. vol 7, 5358.

Wood, R. T., \& Williams, R. J. (2011). Comparative Profile of The Internet Gambler:

Demographic Characteristics, Game-Play Patterns, And Problem Gambling Status. New media \& Society13(7) 1123-1141. 